\title{
FUNDO PARTIDÁRIO E FUNDO ESPECIAL DE FINANCIAMENTO DE CAMPANHA: ANÁLISE SOBRE AS ALTERAÇÕES PROPOSTAS PELO PROJETO DO NOVO CÓDIGO ELEITORAL APROVADO PELA CÂMARA DOS DEPUTADOS
}

\author{
Denise Goulart Schlickmann ${ }^{1}$ \\ Orides Mezzaroba ${ }^{2}$
}

\section{RESUMO}

A Câmara dos Deputados aprovou o Projeto de Lei $n^{\circ} 112 / 2021$, sobre o novo Código Eleitoral, o qual se encontra em discussão no Senado Federal. Considerando as inúmeras alterações operadas pelo referido projeto que recaem sobre o Fundo Partidário e o Fundo Especial de Financiamento de Campanha, objetiva-se analisar os seus impactos, avanços e retrocessos em relação à legislação atual. O estudo irá tratar os aspectos estruturais desde as normas que determinam o seu recebimento, a sua aplicação e a prestação de contas à Justiça Eleitoral pelos partidos políticos.

Palavras-chave: Fundo Partidário. Fundo Especial de Financiamento de Campanha. Partidos Políticos. Eleições. Reforma eleitoral. Código Eleitoral.

\section{PARTY FUND AND SPECIAL CAMPAIGN FINANCING FUND: ANALYSIS ON THE AMENDMENTS PROPOSED BY THE NEW ELECTORAL CODE PROJECT APPROVED BY THE CHAMBER OF DEPUTIES}

\begin{abstract}
The Chamber of Deputies approved Bill No. 112/2021, on the new Electoral Code, which is under discussion in the Federal Senate. Considering the numerous changes operated by the aforementioned project that fall on the Party Fund and the Special Fund for Campaign Financing, the objective is to analyze its impacts, advances and setbacks in relation to current legislation. The study will address the structural aspects from the norms that determine their receipt, their application and accountability to the Electoral Justice by political parties.
\end{abstract}

\footnotetext{
${ }^{1}$ Doutoranda no Programa de Pós-Graduação em Direito da Universidade Federal de Santa Catarina. Mestra em Direito pela UFSC. Bacharel em Ciências Econômicas, Ciências Contábeis e Direito, pela Universidade Federal de Santa Catarina (UFSC). Pós-graduada em Auditoria Governamental pela FEPESE/UFSC, e em Direito Eleitoral pela UNIVALI. Membro do Núcleo de Inteligência da Justiça Eleitoral. Secretária de Controle Interno e Auditoria do TRE/SC. Conferencista na área de direito eleitoral. Autora da obra Financiamento de Campanhas Eleitorais, na décima edição, pela Editora Juruá. Coautora da obra Tratado de Direito Eleitoral, pela Editora Fórum. Coautora da obra Tópicos Avançados de Direito Processual Eleitoral, pela Editora Arraes. Coautora da obra Dicionário das Eleições, pela Editora Juruá. Organizadora e coautora da obra Questões Eleitorais Contemporâneas: uma análise por servidores da Justiça Eleitoral, pela Editora Plácido.

2 Professor dos Programas de Mestrado e Doutorado em Direito da UFSC. Coordenador do Programa de Mestrado Profissional em Direito da UFSC. Presidente do Conselho Nacional de Pesquisa e Pós-Graduação em Direito - CONPEDI. Pesquisador de Produtividade do CNPq.
} 
Keywords: Party Background. Special Campaign Financing Fund. Political parties. Elections. Electoral reform. Electoral Code.

\section{INTRODUÇÃO}

A Câmara dos Deputados aprovou o Projeto de Lei no 112/2021, sobre o novo Código Eleitoral. Referido projeto tramita no Senado Federal e pende de apreciação final. Contudo, ainda que não consolidado o texto final, do exame do projeto aprovado exsurgem questões importantíssimas diretamente relacionadas ao recebimento e aplicação de fundos públicos por partidos políticos e candidatos, bem como relacionadas à transparência de sua aplicação e sua prestação de contas à Justiça Eleitoral.

Ainda que seja evidente que o Código Eleitoral (Lei no 4.737/1965), datado de 1965, encontra-se revogado na maciça maioria de seus dispositivos e que hoje a matéria encontre-se regulamentada, em grande parte, em dois diplomas legais esparsos (a Lei dos Partidos Políticos - Lei n 9 9.096/1995 e a Lei das Eleições - Lei n ${ }^{\circ}$ 9.504/1997), a construção de um novo código exige atenção e refletida análise em suas disposições.

Isso porque, como é natural em um código, nele estarão reunidas todas as disposições legais relativas aos partidos políticos e às eleições no Brasil. Alterações nas regras que atualmente estão em vigor precisam ser vistas sob a perspectiva de quanto refletem positivamente ou não sobre o sistema eleitoral em vigor.

A área de financiamento de partidos políticos e candidatos, nesse norte, é um tema especialmente sensível. Principalmente porque a evolução da matriz de financiamento partidário e eleitoral revela-se cada vez mais predominantemente pública, ainda que permitidas doações de pessoas físicas.

Nesse universo de financiamento partidário e eleitoral, é importante, no contexto de profundas alterações que podem ser consolidadas a partir da aprovação do novo Código Eleitoral, examinar o que pensa a Câmara Federal a respeito desse tema tão caro à democracia brasileira.

$\mathrm{O}$ presente artigo tem por objetivo analisar os impactos, avanços e retrocessos em relação à legislação em vigor. O problema de fundo do artigo está em responder se a proposta do novo Código Eleitoral trará ou não contribuições significativas para o fortalecimento das organizações partidárias e, finalmente para a democracia 


\section{FUNDO PARTIDÁRIO E FUNDO ESPECIAL DE FINANCIAMENTO DE CAMPANHA: \\ ANÁLISE SOBRE AS ALTERAÇÕES PROPOSTAS PELO PROJETO DO NOVO CÓDIGO ELEITORAL \\ APROVADO PELA CÂMARA DOS DEPUTADOS}

representativa. $\mathrm{O}$ método de abordagem será o dedutivo, com procedimentos de pesquisa fundamentados em referências legais e jurisprudenciais.

\section{FUNDOS PÚBLICOS DE FINANCIAMENTO PARTIDÁRIO E ELEITORAL}

Os fundos públicos que financiam partidos políticos e as eleições brasileiras são o Fundo Especial de Assistência Financeira aos Partidos Políticos (Fundo Partidário) e o Fundo Especial de Financiamento de Campanha.

O Fundo Partidário está, atualmente, regulamentado pela Lei dos Partidos Políticos, a Lei $n^{\circ}$ 9.096/1995, que, em seu art. 38, dispõe sobre a sua composição:

Art. 38. O Fundo Especial de Assistência Financeira aos Partidos Políticos (Fundo Partidário) é constituído por:

I - multas e penalidades pecuniárias aplicadas nos termos do Código Eleitoral e leis conexas;

II - recursos financeiros que lhe forem destinados por lei, em caráter permanente ou eventual;

III - doações de pessoa física ou jurídica, efetuadas por intermédio de depósitos bancários diretamente na conta do Fundo Partidário;

IV - dotações orçamentárias da União em valor nunca inferior, cada ano, ao número de eleitores inscritos em 31 de dezembro do ano anterior ao da proposta orçamentária, multiplicados por trinta e cinco centavos de real, em valores de agosto de 1995.

A sua distribuição, por sua vez, está disciplinada nos arts. 40 e 42 da mesma norma, que prevê que os recursos serão repassados pela União ao Tribunal Superior Eleitoral, que os repassará aos partidos políticos:

Art. 40. A previsão orçamentária de recursos para o Fundo Partidário deve ser consignada, no Anexo do Poder Judiciário, ao Tribunal Superior Eleitoral.

$\S 1^{\circ} \mathrm{O}$ Tesouro Nacional depositará, mensalmente, os duodécimos no Banco do Brasil, em conta especial à disposição do Tribunal Superior Eleitoral.

$\S 2^{\circ} \mathrm{Na}$ mesma conta especial serão depositadas as quantias arrecadadas pela aplicação de multas e outras penalidades pecuniárias, previstas na Legislação Eleitoral.

Art. 41. O Tribunal Superior Eleitoral, dentro de cinco dias, a contar da data do depósito a que se refere o $\S 1^{\circ}$ do artigo anterior, fará a respectiva distribuição aos órgãos nacionais dos partidos, obedecendo aos seguintes critérios:

I - um por cento do total do Fundo Partidário será destacado para entrega, em partes iguais, a todos os partidos que tenham seus estatutos registrados no Tribunal Superior Eleitoral;

II - noventa e nove por cento do total do Fundo Partidário serão distribuídos aos partidos que tenham preenchido as condições do art. 13, na proporção dos votos obtidos na última eleição geral para a Câmara dos Deputados.

Art. 41-A. Do total do Fundo Partidário:

I - 5\% (cinco por cento) serão destacados para entrega, em partes iguais, a todos os partidos que atendam aos requisitos constitucionais de acesso aos recursos do Fundo Partidário; e 
II - 95\% (noventa e cinco por cento) serão distribuídos aos partidos na proporção dos votos obtidos na última eleição geral para a Câmara dos Deputados.

Parágrafo único. Para efeito do disposto no inciso II, serão desconsideradas as mudanças de filiação partidária em quaisquer hipóteses.

Art. 42. Em caso de cancelamento ou caducidade do órgão de direção nacional do partido, reverterá ao Fundo Partidário a quota que a este caberia. (grifou-se)

Além da disciplina de sua distribuição, a Lei dos Partidos Políticos (Lei no

9.096/1995) limita a aplicação desses recursos a hipóteses muito específicas:

Art. 44. Os recursos oriundos do Fundo Partidário serão aplicados:

I - na manutenção das sedes e serviços do partido, permitido o pagamento de pessoal, a qualquer título, observado, do total recebido, os seguintes limites:

a) $50 \%$ (cinquenta por cento) para o órgão nacional;

b) $60 \%$ (sessenta por cento) para cada órgão estadual e municipal;

II - na propaganda doutrinária e política;

III - no alistamento e campanhas eleitorais;

IV - na criação e manutenção de instituto ou fundação de pesquisa e de doutrinação e educação política, sendo esta aplicação de, no mínimo, vinte por cento do total recebido.

V - na criação e manutenção de programas de promoção e difusão da participação política das mulheres, criados e executados pela Secretaria da Mulher ou, a critério da agremiação, por instituto com personalidade jurídica própria presidido pela Secretária da Mulher, em nível nacional, conforme percentual que será fixado pelo órgão nacional de direção partidária, observado o mínimo de 5\% (cinco por cento) do total;

VI - no pagamento de mensalidades, anuidades e congêneres devidos a organismos partidários internacionais que se destinem ao apoio à pesquisa, ao estudo e à doutrinação política, aos quais seja o partido político regularmente filiado;

VII - no pagamento de despesas com alimentação, incluindo restaurantes e lanchonetes;

VIII - na contratação de serviços de consultoria contábil e advocatícia e de serviços para atuação jurisdicional em ações de controle de constitucionalidade e em demais processos judiciais e administrativos de interesse partidário, bem como nos litígios que envolvam candidatos do partido, eleitos ou não, relacionados exclusivamente ao processo eleitoral

IX - (VETADO);

$\mathrm{X}$ - na compra ou locação de bens móveis e imóveis, bem como na edificação ou construção de sedes e afins, e na realização de reformas e outras adaptações nesses bens;

XI - no custeio de impulsionamento, para conteúdos contratados diretamente com provedor de aplicação de internet com sede e foro no País, incluída a priorização paga de conteúdos resultantes de aplicações de busca na internet, mediante o pagamento por meio de boleto bancário, de depósito identificado ou de transferência eletrônica diretamente para conta do provedor, o qual deve manter conta bancária específica para receber recursos dessa natureza, proibido nos 180 (cento e oitenta) dias anteriores à eleição

Além do que disciplina Lei dos Partidos Políticos, a ADI no 5617 obriga que tais recursos financiem diretamente campanhas femininas, no percentual mínimo de 30\%, devendo ser observado percentual ainda maior caso no número de candidatas de um mesmo partido seja também superior. Consulta do Tribunal Superior Eleitoral (CTA 0600306-47), 


\section{FUNDO PARTIDÁRIO E FUNDO ESPECIAL DE FINANCIAMENTO DE CAMPANHA: ANÁLISE SOBRE AS ALTERAÇÕES PROPOSTAS PELO PROJETO DO NOVO CÓDIGO ELEITORAL APROVADO PELA CÂMARA DOS DEPUTADOS}

objeto de decisão específica também do Supremo Tribunal Federal (ADPF no 738), determinou que tais recursos sejam aplicados pelos partidos políticos observando também a proporcionalidade de candidaturas negras.

A reforma eleitoral de 2017 (Lei n ${ }^{\circ}$ 13.487/2017), por sua vez, criou fonte de recursos públicos de financiamento de campanhas eleitorais, o Fundo Especial de Financiamento da Democracia (FFD).

Criado o fundo especial, a Lei $\mathrm{n}^{\circ}$ 9.504/1997, alterada pela Lei $\mathrm{n}^{\circ}$ 13.488/2017, passou a dispor quanto aos critérios de sua distribuição aos partidos políticos:

Art. 16-D. Os recursos do Fundo Especial de Financiamento de Campanha (FEFC), para o primeiro turno das eleições, serão distribuídos entre os partidos políticos, obedecidos os seguintes critérios

I - $2 \%$ (dois por cento), divididos igualitariamente entre todos os partidos com estatutos registrados no Tribunal Superior Eleitoral;

II - 35\% (trinta e cinco por cento), divididos entre os partidos que tenham pelo menos um representante na Câmara dos Deputados, na proporção do percentual de votos por eles obtidos na última eleição geral para a Câmara dos Deputados;

III - 48\% (quarenta e oito por cento), divididos entre os partidos, na proporção do número de representantes na Câmara dos Deputados, consideradas as legendas dos titulares;

IV - 15\% (quinze por cento), divididos entre os partidos, na proporção do número de representantes no Senado Federal, consideradas as legendas dos titulares.

Já quanto à distribuição desses recursos aos candidatos, a Lei $\mathrm{n}^{\circ}$

13.487/2017 dispôs:

Art. 16-C. [...] $\S 7^{0}$ Os recursos de que trata este artigo ficarão à disposição do partido político somente após a definição de critérios para a sua distribuição, os quais, aprovados pela maioria absoluta dos membros do órgão de direção executiva nacional do partido, serão divulgados publicamente.

Delineados os fundos públicos de financiamento partidário e eleitoral, passa-se a examinar as inovações dispostas no projeto do novo Código Eleitoral aprovado pela Câmara dos Deputados de maior impacto sobre o tema.

Primeiro aspecto que merece destaque é a manutenção da previsão de composição dos recursos do Fundo Partidário com recursos recebidos de doações de pessoas jurídicas (art. 63, III). A redação data da versão original da Lei n ${ }^{\circ}$ 9.096/1995 e, portanto, muito anterior à ADI 4650 que veda o financiamento partidário e eleitoral por pessoas jurídicas. De ressaltar-se que o projeto se alinha à declaratória quando fixa como fonte vedada a doação de pessoas jurídicas (art. 59, II). Contudo, ao permitir que tais recursos componham o Fundo Partidário, acaba por autorizar que o financiamento empresarial ocorra de forma indireta tanto a partidos políticos quanto a campanhas eleitorais, revelando uma antinomia 
normativa que padece de correção. Rememore-se que o Fundo Partidário é atualmente uma das principais fontes de financiamento dos partidos políticos. E o descompasso legislativo agrava-se ao ser constatado que, enquanto as doações de pessoas físicas para campanhas eleitorais estão limitadas no projeto, para tais doações de pessoas jurídicas - uma vez que não estão disciplinadas - sequer há o estabelecimento de limites, podendo repercutir de forma danosa no financiamento partidário direto e no financiamento de campanhas eleitorais, uma vez que a aplicação em campanhas eleitorais dos recursos do Fundo Partidário é perfeitamente legal.

$\mathrm{O}$ art. 36 do projeto passa a prever, em seu inciso IX, que os estatutos partidários devem dispor sobre os "critérios de distribuição dos recursos do Fundo Partidário entre os órgãos de nível municipal, estadual ou distrital e nacional que compõem o partido". A inovação é positiva, uma vez que atualmente, a ausência de obrigatoriedade de tais normas no estatuto partidário propicia que a distribuição desses recursos entre as mais diversas esferas partidárias dependa unicamente de decisão do diretório nacional. A regra favorece, pois, o fortalecimento da democracia intrapartidária.

O projeto aprovado acresce, ainda, a dispositivo que constava na versão anterior e que impedia o uso de recursos do Fundo Partidário para "quitação de multas relativas a atos infracionais, ilícitos penais, administrativos e eleitorais ou para a quitação de encargos decorrentes de inadimplência de pagamentos", consolidando farta jurisprudência da Justiça Eleitoral, a exigência de comprovação de dolo específico (art. 67, § $7^{\circ}$ ). A exigência, por si só, acaba por autorizar, a priori, o uso de tais recursos para estas hipóteses, antes vedadas, eis que a comprovação do dolo torna dificultado o óbice ao uso indistinto dos recursos.

Aspecto positivo deve ser ressaltado no que diz respeito à distribuição desses recursos entre os partidos políticos. Considerando-se que o principal critério é o da representação proporcional na Câmara dos Deputados, passam a ser computados em dobro "os votos dados a mulheres, a negros e a indígenas [...], aplicando-se uma única vez por pleito, considerado o sexo ou a raça" (art. 65, parágrafo único, II). A medida contribui para importante ação afirmativa que busca incentivar a participação política de mulheres, hoje minoria entre os representantes eleitos nos poderes Executivo e Legislativo.

Ainda no que se refere às políticas de afirmação, ressalta-se aspecto positivo diretamente relacionado à aplicação obrigatória dos recursos públicos recebidos para financiar 


\section{FUNDO PARTIDÁRIO E FUNDO ESPECIAL DE FINANCIAMENTO DE CAMPANHA: ANÁLISE SOBRE AS ALTERAÇÕES PROPOSTAS PELO PROJETO DO NOVO CÓDIGO ELEITORAL APROVADO PELA CÂMARA DOS DEPUTADOS}

candidaturas negras, observada a proporcionalidade verificada dentre as candidaturas do partido político (art. 380, IV).

A utilização de recursos do Fundo Partidário é delimitada exaustivamente na Lei dos Partidos Políticos. O projeto de lei aprovado pela Câmara dos Deputados insere o inciso XII no art. 67, acrescendo às hipóteses restritas de aplicação dos recursos hipótese genérica que culmina por invalidar as restrições antes existentes. De anotar-se que as hipóteses legais, inicialmente apenas quatro, foram sendo ampliadas com as sucessivas reformas eleitorais e já somavam onze. O projeto aprovado dispõe que os recursos do Fundo Partidário podem ser aplicados para custear "outros gastos e interesse partidário, conforme deliberação do partido político". Claramente reduz-se as possibilidades de controle de uso deste fundo público. No mesmo sentido observa-se o acréscimo da expressão "discricionariedade" no $\S 3^{\circ}$ do mesmo artigo, que passa a prever que além de os recursos não estarem sujeitos ao regime licitatório estariam assegurados ao partido político "autonomia e discricionariedade para contratar e realizar despesas".

Já no que concerne ao Fundo Especial de Financiamento de Campanha, o projeto mantém a concentração da decisão sobre os critérios de sua aplicação exclusivamente pelo órgão de direção nacional (art. 378, § $3^{\circ}$ ), concentrando o poder decisório na cúpula partidária. Essa concentração de poder potencializa a manutenção das mesmas estruturas de poder intrapartidárias indefinidamente, frustrando as práticas democráticas na definição da aplicação dos recursos públicos, retirando também a desejada transparência nessa definição, permitindo a concentração de recursos em poucas candidaturas. O projeto de lei aprovado perde a oportunidade de estabelecer critérios objetivos e transparentes, hábeis a privilegiar a equidade na distribuição dos recursos públicos, tanto quanto possível ante a necessária autonomia partidária na definição de suas estratégias eleitorais. A definição concentrada dos critérios, sem mecanismos que privilegiem a ampla participação das demais esferas partidárias e dos filiados aos partidos políticos possibilita que os recursos públicos, cujo fundo instituído prevê tenham finalidade de financiar campanhas eleitorais, possam ser direcionados também de forma exclusiva. À mingua da definição de critérios legais de distribuição do Fundo Especial de Financiamento de Campanha, exsurge de forma relevante o potencial desvio de finalidade no uso dessa espécie de recursos, os quais não se pode esquecer, são públicos. 
Ainda em relação ao Fundo Especial de Financiamento de Campanha, o projeto de lei aprovado pela Câmara dos Deputados prevê que, ao contrário do que prevê a Lei ${ }^{\circ}$ 9.504/1997, os recursos não utilizados pelos candidatos não sejam de pronto recolhidos ao Tesouro Nacional, mas devolvidos ao Diretório Nacional para que possa redistribuí-los aos candidatos até a véspera da data de entrega da prestação de contas (art. 378, § $4^{\circ}$ ). Uma vez que deixa de existir a obrigação de devolução dos recursos ao Tesouro Nacional no ato da prestação de contas, embora o texto do projeto não explicite, tais recursos, se não utilizados integralmente, à míngua de disposição legal em sentido oposto, devem permanecer com os próprios partidos políticos.

$\mathrm{O}$ art. 380 do projeto, em oposição à regra vigente na última eleição, estatuída pelo Tribunal Superior Eleitoral a partir do conceito de interesse jurídico na eleição, permite que os recursos do Fundo Especial de Financiamento de Campanha sejam distribuídos a candidatos à eleição proporcional, para a qual não há coligação partidária, desde que haja entre os partidos políticos coligação na eleição majoritária. Subverte-se, dessa forma, a lógica de apoio aos partidos políticos com interesse jurídico na eleição - que se verifica apenas na existência de coligação - possibilitando-se que os recursos sejam destinados por determinado partido político a campanhas proporcionais de partidos que com ele concorrem e, portanto, são dele rivais. O expediente cria as condições indesejáveis para o desvio de finalidade na aplicação dos recursos públicos.

O projeto prevê, ainda, no mesmo dispositivo, a possibilidade de aplicação dos recursos do Fundo Especial de Financiamento de Campanha no que denomina "estratégia eleitoral relacionada ao financiamento direto, indireto, cruzado ou estimável em dinheiro de campanhas, com vistas ao impulsionamento da candidatura do postulante doador”. A norma é aberta e um tanto vaga, e pode, de igual sorte, obscurecer o conceito de interesse jurídico e, portanto, legítimo, na aplicação dos recursos, eventualmente subvertendo os critérios fixados para sua aplicação pelo diretório nacional.

\section{PRESTAÇÃO DE CONTAS E COMPETÊNCIA DA JUSTIÇA ELEITORAL PARA FISCALIZAÇÃO}

Ressaltado o viés público da maciça maioria dos recursos que financiam partidos políticos e candidatos, para além da flexibilização das regras de recebimento e 


\section{FUNDO PARTIDÁRIO E FUNDO ESPECIAL DE FINANCIAMENTO DE CAMPANHA: ANÁLISE SOBRE AS ALTERAÇÕES PROPOSTAS PELO PROJETO DO NOVO CÓDIGO ELEITORAL APROVADO PELA CÂMARA DOS DEPUTADOS}

aplicação, o projeto de lei aprovado na Câmara dos Deputados fere de forma avassaladora o instituto que abriga o dever de prestar contas desses recursos, minando também as possibilidades de atuação da Justiça Eleitoral no exercício de sua competência originária de exame e julgamento de contas.

$\mathrm{O}$ projeto busca claramente restringir o ato de prestar contas à sua vinculação com a escrituração contábil digital (ECD), em detrimento da apresentação de prova do cumprimento das obrigações de natureza eleitoral (art. 69, caput). Mais não fosse, restringe a competência de exame de contas da Justiça Eleitoral à mera aferição de questões específicas, consolidadas no $\S 2^{\circ}$ do mesmo artigo, que não são passíveis de extração direta de escrituração contábil, retirando-lhe a devida competência de fiscalização ampla da utilização dos recursos públicos, litteris:

Art. $69[\ldots] \S 2^{\circ}$ Deverão ser analisados pela Justiça Eleitoral os seguintes dados informados na ECD:

I - existência de doações vedadas ou de origem não identificada;

II - o correto valor no repasse de cotas destinadas à fundação e ao programa de incentivo à participação das mulheres na política em relação ao montante recebido do Fundo Partidário;

III - regularidade na inscrição das pessoas jurídicas prestadoras de serviços de qualquer natureza no CNPJ;

IV - excesso ou desvio de finalidade dos recursos do Fundo Partidário

em despesas com pessoal;

V-aplicação de recursos em situações diversas das previstas no $\S 1^{\circ}$ do

art. 61 e no art. 67 desta Lei.

Anote-se que o inciso XII do art. 67, já examinado, prevê a aplicação ampla e genérica de recursos, o que, por si só, praticamente inviabiliza o apontamento de qualquer restrição.

O projeto acaba por concentrar a prestação de contas em seus aspectos exclusivamente contábeis, em clara minimização do dever de prestar contas do cumprimento das obrigações de natureza eleitoral. É de ser lembrado, ainda, que a Justiça Eleitoral não detém a competência para fiscalizar contabilmente os partidos políticos. Como ramo de justiça especializada que é, concentra o seu exame de regularidade de contas no cumprimento das obrigações de natureza eminentemente eleitoral. Sequer conta em seus quadros de primeiro grau com técnicos contábeis aptos ao exame contábil de contas a que se destinaria o SPED. Lembre-se que é justamente no primeiro grau que são examinadas a maior parte das contas prestadas, pois o número de diretórios municipais de partidos políticos é sensivelmente superior ao número de diretórios estaduais e nacionais. Além disso, os partidos políticos são pessoas jurídicas de direito privado e apenas por essa condição estão sujeitos a todas as regras 
impostas às demais pessoas jurídicas, as quais sofrem tanto regulamentação quanto fiscalização por órgãos específicos, em tudo distintos da Justiça Eleitoral. Ou seja, o dever constitucional de prestar contas imposto aos partidos políticos à Justiça Eleitoral não tem por finalidade aferir a contabilidade do partido político (competência de outros órgãos, como os fazendários, v.g.), mas sim o cumprimento das obrigações a que está sujeito em razão das normas eleitorais. É, pois, muito mais jurídico do que propriamente financeiro e não é contábil. Para a Justiça Eleitoral o acesso ao SPED é instrumento auxiliar. Mero subsídio para aferição do cumprimento das obrigações de natureza eleitoral, para o que a simples contabilização não é suficiente.

O projeto prevê, ainda, rito extremamente simplificado, em que apontamento de incorreções na ECD gerariam mera impugnação de natureza administrativa, encaminhada ao Ministério Público Eleitoral para manifestação, seguida de julgamento e recurso administrativo, culminando por estabelecer sanção, em caso de desaprovação, de irrisórios dois mil a trinta mil reais (art. 69, $\S \S 5^{\circ}$ a $9^{\circ}$ ). Além de prever o juízo de razoabilidade e proporcionalidade na aplicação da sanção, o projeto desconsidera a insignificância da sanção diante de diretórios nacionais de partido político que prestam contas de centenas de milhões de reais de recursos públicos.

Mais não fosse, o projeto estabelece aprovação de contas praticamente tácita caso não a pontados equívocos pela unidade técnica no exame das contas (art. 69, § 10).

As novas regras reduzem o prazo prescricional para julgar contas de cinco para três anos, tornando ainda mais provável a consequência de extinção dos processos, que passa a ser prevista na norma (art. 69, §12). É evidente que no caso de prestações de contas de grande vulto ou de maior complexidade há a natural exigência de tempo substancial de análise técnica. E aqui mais um entrave se verifica à ampla fiscalização de contas.

E aqui cabe ressaltar que o novo projeto aprovado pela Câmara dos Deputados reduz substancialmente o status dos processos de contas de judiciais a administrativos, o que por si só impacta diretamente na aplicação de sanções (cada vez mais limitadas), eis que obstado o trânsito em julgado (art. 69, § 12 e art. 416). O conceito de processo administrativo, em evidente retrocesso à evolução do caráter judicial que confere estabilidade às decisões proferidas pela Justiça Eleitoral, principalmente no que se refere à aplicação de sanções. Considerando-se que os partidos políticos - ao contrário dos candidatos - possuem natureza permanente, seguindo-se ao exercício financeiro a que se referem as 


\section{FUNDO PARTIDÁRIO E FUNDO ESPECIAL DE FINANCIAMENTO DE CAMPANHA: ANÁLISE SOBRE AS ALTERAÇÕES PROPOSTAS PELO PROJETO DO NOVO CÓDIGO ELEITORAL APROVADO PELA CÂMARA DOS DEPUTADOS}

contas imediatamente exercício seguinte, a execução de sanções torna-se praticamente inviável no escopo administrativo dos processos, cujas decisões não transitam em julgado e que precisam afetar os exercícios seguintes dos quais o partido político prestará contas nos anos subsequentes.

De anotar-se a singularidade de que a perda do caráter judicial aos processos de prestação de contas prevista no código não se estende às prestações de contas de campanha eleitoral e que é justamente no processo de contas partidário que se concentram os maiores volumes de recursos submetidos a julgamento.

E na sequência da atrofia das regras de prestação de contas, o projeto passa a prever no $\S 13$ do mesmo artigo 69 a aprovação com ressalvas direta caso as falhas eventualmente encontradas não ultrapassem " $20 \%$ do total recebido do Fundo Partidário no respectivo ano", desconsiderando o juízo de gravidade das falhas, que podem não ser substanciais nominalmente, mas que podem apontar a irregularidades de extrema gravidade.

Mas, sem dúvida alguma, é no art. 70 do projeto aprovado que se encontra a regra mais danosa relacionada à prestação de contas de partidos políticos, em verdadeira blindagem à sua atuação na esfera financeira, atribuindo a empresas terceirizadas de auditoria a função de aferição de contas. Veja-se:

\footnotetext{
Art. 70. É facultado aos órgãos partidários, de qualquer esfera, contratar instituições privadas de auditoria e de conformidade previamente cadastradas perante a Justiça Eleitoral para acompanhar e fiscalizar a execução financeira anual sob a responsabilidade do partido político.

$\S 1^{\circ} \mathrm{Na}$ hipótese prevista neste artigo, a prestação de contas do órgão do partido político, a ser apresentada à Justiça Eleitoral, será acompanhada do número de protocolo da escrituração contábil no Sped do exercício findo, bem como de relatório elaborado pela instituição de auditoria e de conformidade que reflita incongruências graves e insanáveis nos dispêndios realizados e, se for o caso, nos recursos aplicados em campanhas eleitorais.

$\$ 2^{\circ}$ A Justiça Eleitoral deverá cadastrar previamente empresas especializadas na prestação dos serviços de auditoria e de conformidade para os fins do caput e do $\S 4^{\circ}$ deste artigo.

$\S 3^{\circ} \mathrm{O}$ processo de prestação de contas dos órgãos partidários previsto no caput deste artigo também terá natureza administrativa e será submetido a julgamento pela Justiça Eleitoral, assegurada ampla defesa, somente podendo ser desaprovadas as contas caso constatadas as situações não sanadas previstas nos $\S \S 2^{\circ}$ e $9^{\circ}$ do art. 69 desta Lei ou quando o relatório de auditoria apresentar incongruências graves e insanáveis na movimentação financeira da agremiação. (grifou-se)
}

A regra traz proteção indesejada aos partidos políticos da atuação direta da fiscalização da Justiça Eleitoral, a qual deve ser conferida ampla e irrestrita possibilidade de aferir o cumprimento das obrigações de natureza eleitoral. Sua atuação - caso a regra se 
estabeleça de forma definitiva com a deliberação do Senado Federal e com a sanção presidencial - se apequena de forma injustificável aos interesses da sociedade.

E é de se registrar que a previsão dessa regra de terceirização da fiscalização de contas, já constante na versão anterior do projeto de lei, restou agravada com o acréscimo da expressão "graves e insanáveis" ao que o projeto chama de "incongruências" a serem apontadas pela instituição privada de auditoria contratada diretamente pelo partido político.

Ao fim e ao cabo, a Justiça Eleitoral receberá, a título de prestação de contas, em troca do que efetivamente deveria receber - as informações integrais relacionadas à arrecadação de recursos, realização de gastos, de molde a viabilizar a aferição do cumprimento de obrigações de natureza eleitoral - apenas um relatório produzido por tais empresas de auditoria, com o que considerarem falhas graves e insanáveis, acompanhados do protocolo de sua escrituração contábil.

Descaracteriza-se, pois, tanto a natureza, quanto a forma e, principalmente, a efetividade do instituto de prestação de contas, justamente aquele aos quais estão submetidas as instituições permanentes que sustentam o regime democrático, os partidos políticos, que em muitas circunstâncias, notadamente nos âmbitos nacional e estadual, movimentam vultosas somas de recursos.

No campo das sanções derivadas do julgamento de contas, no que se refere à assunção de obrigações por esferas partidárias distintas, o projeto prevê no art. 410 a ausência de restrição da espécie de recurso utilizada para quitação de dívidas. Ora, a possibilidade de que diferentes esferas partidárias assumam obrigações de outras esferas sem qualquer restrição da fonte do recurso utilizado para quitação de dívidas possibilita que partidos políticos com sanções aplicadas pela Justiça Eleitoral impeditivas de recebimento de recursos públicos alcancem tais recursos pela via indireta, ou seja, pelo pagamento de suas dívidas por outros órgãos partidários não impedidos de tal recebimento. A medida retira a eficácia na aplicação de sanções desse gênero.

A regra vigente, que não foi mantida no projeto aprovado, não permite que determinado partido político assuma obrigações de outro e quite tais obrigações com recursos do Fundo Partidário se o órgão que transfere a dívida esteja proibido de receber essa espécie de recursos. A medida resguarda a eventual burla à aplicação da sanção pelo seu recebimento indireto pela via do pagamento de dívidas do partido sancionado com essa espécie de recursos. 


\section{FUNDO PARTIDÁRIO E FUNDO ESPECIAL DE FINANCIAMENTO DE CAMPANHA: ANÁLISE SOBRE AS ALTERAÇÕES PROPOSTAS PELO PROJETO DO NOVO CÓDIGO ELEITORAL APROVADO PELA CÂMARA DOS DEPUTADOS}

Ainda no que se refere às contas partidárias, o projeto mantém a previsão de que os órgãos partidários, agora em qualquer nível (a Lei dos Partidos Políticos em vigor prevê tal faculdade, ainda que indevidamente, apenas aos diretórios municipais), encaminhem à Justiça Eleitoral meras declarações de ausência de prestação de contas, em oposição à obrigação constitucional de prestar contas $\left(\operatorname{art} .72, \S 1^{\circ}\right.$ ). Nasce o projeto de lei, pois, eivado de inconstitucionalidade, uma vez que a obrigação de prestar contas é pressuposto constitucional de existência dos partidos políticos disposta no art. 17 da Constituição Federal, litteris:

\footnotetext{
Art. 17. É livre a criação, fusão, incorporação e extinção de partidos políticos, resguardados a soberania nacional, o regime democrático, o pluripartidarismo, os direitos fundamentais da pessoa humana e observados os seguintes preceitos: I - caráter nacional;

II - proibição de recebimento de recursos financeiros de entidade ou governo estrangeiros ou de subordinação a estes;

III - prestação de contas à Justiça Eleitoral;

IV - funcionamento parlamentar de acordo com a lei. (grifou-se)
}

Em razão do dispositivo que já estava em vigor, a Justiça Eleitoral disciplinou o processamento da declaração de ausência de movimentação de recursos como efetiva prestação de contas sem movimentação financeira, sujeita a rito próprio, dada a inviabilidade de considerá-la, como a redação previa, como dispensa legal de prestação de contas. Vê-se que o projeto, além de manter o instituto evidentemente inconstitucional, ampliou indevidamente o seu uso para contemplar também as esferas nacional e estadual dos partidos políticos.

A propósito, importa destacar que um partido político em plena vigência e funcionamento não prescinde das necessárias condições materiais, ainda que escassas e na forma estimável em dinheiro, ou seja, em bens e serviços, daí porque tal circunstância - de ausência de movimentação de recursos - é absolutamente irreal.

No que diz respeito aos partidos políticos obrigados à prestação de contas de natureza eleitoral, ao contrário da regra sedimentada pela Justiça Eleitoral de obrigação de prestar contas em todas as esferas em todas as eleições o projeto aprovado passa a dispor no art. 418 que apenas os órgãos partidários que participarem das eleições devem contas à Justiça Eleitoral. A regra atualmente vigente da universalidade da obrigação de prestar contas evita que recursos transitem por órgãos partidários que não participam diretamente da eleição e que eventualmente repassem esses recursos àqueles diretamente nela envolvidos, viabilizando a 
ampla fiscalização do financiamento eleitoral. Ainda que persista a obrigação de prestar contas anualmente, a ausência de aferição ao tempo em que os demais prestam suas contas certamente pode causar prejuízo à correta aferição dos recursos financiadores de campanha eleitoral.

O art. 422 do projeto, por sua vez, desobriga da prestação de contas eleitoral os diretórios nacionais e estaduais de partidos políticos que repassarem exclusivamente recursos dos fundos públicos a candidatos, ficando a obrigação de prestar contas diferida no tempo para a ocasião da prestação de contas anual. No mesmo sentido, dispensa os diretórios municipais da prestação de contas quando não utilizarem recursos do Fundo Especial de Financiamento de Campanha nas eleições gerais. Ora, a dispensa conferida no projeto de lei frustra a possibilidade de cruzamento de dados e confronto das informações prestadas pelos próprios candidatos, que não raras vezes divergem daquelas prestadas pelos próprios partidos políticos, enfraquecendo os instrumentos de aferição de regularidade das contas. A inserção dessas informações apenas na prestação de contas anual impede a sua repercussão nas contas julgadas por ocasião da eleição.

O projeto passa a exigir a existência de provas pré-constituídas para que a autoridade judicial possa promover a apuração da veracidade dos gastos eleitorais declarados (art. 423, § $1^{\circ}$ ), consistente na apresentação de provas aptas pelos respectivos fornecedores para demonstrar a prestação de serviços ou a entrega dos bens contratados ou, ainda, a quebra do sigilo bancário e fiscal do fornecedor ou de terceiros envolvidos. As regras vigentes permitem que a apuração se faça sem que haja prova pré-constituída, inviabilizadora da medida em si. $\mathrm{O}$ projeto retira ainda das regras vigentes a possibilidade de que a autoridade judicial determine a realização de busca e apreensão, exibição de documentos e demais medidas antecipatórias de produção de prova admitidas pela legislação. Consolidam-se severas restrições ao exercício do controle e fiscalização concomitante do financiamento eleitoral.

O projeto restringe, ainda, a transparência e o controle social sobre os relatórios financeiros encaminhados durante a campanha eleitoral ( $\operatorname{art.} 432, \S \S 3^{\mathrm{o}}$ e $4^{\mathrm{o}}$ ), cuja intempestividade ou omissão de apresentação deixam de configurar irregularidades graves e passam a ser qualificadas como irregularidades "de natureza meramente formal”. Por fim, na hipótese de omissão, retira-se a possibilidade de exame, pelo órgão julgador, da gravidade da infração para estabelecer que "acarretará exclusivamente a aprovação com ressalvas" das 


\section{FUNDO PARTIDÁRIO E FUNDO ESPECIAL DE FINANCIAMENTO DE CAMPANHA: ANÁLISE SOBRE AS ALTERAÇÕES PROPOSTAS PELO PROJETO DO NOVO CÓDIGO ELEITORAL APROVADO PELA CÂMARA DOS DEPUTADOS}

contas. Ressalte-se que está justamente na publicidade de dados a premissa fundante de transparência material das contas, viabilizadora dos confrontos de dados com as informações disponíveis em outros órgãos públicos, hoje executados como ações de inteligência pelo Núcleo de Inteligência da Justiça Eleitoral. Tais ações buscam alcançar a realidade das contas, quer sob o ponto de vista de capacidade operacional dos fornecedores, quer sob o ponto de vista de capacidade econômica dos doadores. Se tais condições não estão presentes, os verdadeiros doadores podem estar ocultos e caracterizar fontes vedadas ou não identificadas e os gastos declarados podem acobertar desvios de recursos ou mesmo a prática de outros ilícitos eleitorais.

No que se refere à devolução de recursos dos fundos públicos por irregularidades constatadas quando do julgamento de contas não prestadas, o projeto passa a prever que tal devolução ocorra apenas na hipótese de que as irregularidades sejam dolosas ou insanáveis (art. 443, $\S 3^{\circ}$ ), inserindo componente de difícil aferição, o que torna por consequência mais difícil a imposição de devolução de recursos públicos mal aplicados ou não comprovados.

\section{CONCLUSÃO}

À medida em que se avultam os recursos públicos financiando partidos políticos e campanhas eleitorais observa-se que a legislação eleitoral retrocede em sua regulamentação, afetando garantias antes presentes de transparência e controle.

O projeto do novo Código Eleitoral recentemente aprovado na Câmara dos Deputados e em discussão no Senado Federal afeta profundamente tanto as regras de distribuição, aplicação e prestação de contas do uso desses recursos à Justiça Eleitoral.

Ainda que as novas normas não se apliquem às próximas eleições dado o descumprimento do princípio constitucional da anualidade inserto no seu art. 16, certo é que há evidente prejuízo também à independência e à possibilidade de atuação da Justiça Eleitoral no dever de julgar as contas prestadas por partidos políticos e candidatos.

Pode-se concluir, pois, que são muito pequenos os avanços normativos operados pelo projeto de Código Eleitoral aprovado pela Câmara dos Deputados frente aos inúmeros retrocessos pontuados neste artigo. Os aspectos positivos que merecem relevo são, 
sem dúvida, as políticas afirmativas de participação política de minorias, notadamente candidaturas femininas e candidaturas negras.

No que toca aos retrocessos evidenciados no projeto aprovado, destaca-se a possibilidade de que pessoas jurídicas permaneçam financiando indiretamente partidos políticos e eleições, apesar da julgada inconstitucionalidade desse expediente, mediante doações ao Fundo Partidário; a possibilidade de utilização dessa espécie de recursos para quitação de multas e infrações, bem como encargos de mora, salvo na condição de comprovação de dolo específico e, por fim, a criação de hipótese genérica de gastos com Fundo Partidário, desvirtuando a sua destinação específica atualmente vigente.

No âmbito do Fundo Especial de Financiamento de Campanha, o projeto aprovado preserva o poder decisório da cúpula partidária sobre sua distribuição nas campanhas eleitorais, potencializando a manutenção de estruturas e a concentração dos recursos em poucas candidaturas; institui mecanismo de devolução de recursos aos diretórios partidários e não ao Tesouro Nacional, possibilitando redistribuições de recursos para além dos criticados critérios estatuídos para a eleição; permite a sua distribuição a candidaturas rivais, distantes do conceito de interesse jurídico na eleição, já que não participantes de coligação nas eleições proporcionais, ora vedadas, possibilitando o desvio de finalidade na aplicação dos recursos.

No que se refere ao instituto da prestação de contas à Justiça Eleitoral, as regras dispostas no projeto aprovado pela Câmara dos Deputados abalam de forma avassaladora os pilares quer de completude e transparência de informações, quer de competência da Justiça Eleitoral para examinar a íntegra dos recursos arrecadados e aplicados, quer nas contas partidárias anuais, quer nas contas eleitorais. Opera-se a redução das contas ao seu nível meramente contábil, distante do efetivo cumprimento das obrigações eleitorais, que não se pode extrair dos registros contábeis brutos; simplifica-se o rito das contas, apequenando-o e retirando-lhe o caráter judicial para fazê-lo administrativo, prejudicando enormemente a estabilidade das decisões e a efetividade de eventuais sanções; de forma ainda mais danosa, blinda os partidos políticos com a possibilidade de praticamente terceirizar o exame de suas contas junto a empresas de auditorias por eles contratadas, cujos relatórios dificilmente podem ser questionados, dadas as restrições das regras previstas no projeto aprovado; permite que partidos impedidos de receber recursos públicos por sanções aplicadas pela Justiça Eleitoral tenham suas obrigações assumidas por outras esferas com recursos desse 


\section{FUNDO PARTIDÁRIO E FUNDO ESPECIAL DE FINANCIAMENTO DE CAMPANHA: ANÁLISE SOBRE AS ALTERAÇÕES PROPOSTAS PELO PROJETO DO NOVO CÓDIGO ELEITORAL APROVADO PELA CÂMARA DOS DEPUTADOS}

mesmo gênero, contornando os efeitos da sanção; prevê regra inconstitucional ao possibilitar que partidos políticos apresentem a título de prestação de contas meras declarações de ausência de movimentação de recursos; restringe as prestações de contas de campanha eleitorais aos partidos que participaram do pleito, retirando o caráter de universalidade dessa obrigação, sedimentado já há muitas eleições, que viabiliza amplo controle e fiscalização; reduz as hipóteses de prestação de contas por partidos políticos, concentrando-se exclusivamente nos recursos públicos, ignorando a importância da aferição do recebimento e aplicação de recursos privados, que preservariam a identidade e a legalidade das fontes financiadoras; passa a exigir a existência de provas pré-constituídas para que a autoridade judicial possa promover a apuração da veracidade dos gastos eleitorais declarado; restringe a transparência e o controle social sobre os relatórios financeiros encaminhados durante a campanha eleitoral, cuja tempestividade e completude são essenciais ao acompanhamento cidadão e à fiscalização dos órgãos de controle e, por fim, reduz as hipóteses de devolução de recursos públicos não comprovados ou aplicados irregularmente à prova de dolo e insanabilidade.

Não há, pois, o que comemorar quanto ao projeto aprovado pela Câmara dos Deputados para o novo Código Eleitoral. Na balança de prós e contras estes superam em muito os poucos pontos positivos que se pode destacar no que se refere aos fundos públicos financiadores de partidos políticos e eleições ou à sua prestação de contas à Justiça Eleitoral. Perde o cidadão. Perde a democracia brasileira.

\section{REFERÊNCIAS}

BRASIL. Câmara dos Deputados. PLP n ${ }^{\circ} 112$, de 3 de agosto de 2021. Dispõe sobre as normas eleitorais e as normas processuais eleitorais brasileiras. Disponível em https://www.camara.leg.br/propostas-legislativas/2292163. Acesso em 1 out 2021.

. Lei no 4.737, de 15 de julho de 1965. Código Eleitoral. Diário Oficial da União, Brasília, DF, 19 jul 1965. Seção 1, p. 6746.

Lei $n^{\circ}$ 9.504, de 30 de setembro de 1997. Estabelece normas para as eleições.

Diário Oficial da República Federativa do Brasil, Brasília, DF, 1 out. 1997. Seção 1, p. 21.801.

. Lei n 9.096, de 19.09.1995. Dispõe sobre partidos políticos, regulamenta os artigos 17 e $14, \S 3^{\circ}$, inciso V, da Constituição Federal. Diário Oficial da República Federativa do Brasil, Brasília, DF, 20 set 1995. Seção 1, p. 14.552. 
Lei 13.487, de 06 de outubro de 2017. Altera as Leis 9.504, de 30.09.1997, e 9.096, de 19.09.1995, para instituir o Fundo Especial de Financiamento de Campanha (FEFC) e extinguir a propaganda partidária no rádio e na televisão. Diário Oficial da República Federativa do Brasil, Brasília, DF, 06.10.2017. Seção 1, p. 1.

Lei 13.488, de 06 de outubro de 2017. Altera as Leis $n^{\circ} \mathrm{s} 9.504$, de 30 de setembro de 1997 (Lei das Eleições), 9.096, de 19 de setembro de 1995, e 4.737, de 15 de julho de 1965 (Código Eleitoral), e revoga dispositivos da Lei n ${ }^{\circ} 13.165$, de 29 de setembro de 2015 (Minirreforma Eleitoral de 2015), com o fim de promover reforma no ordenamento políticoeleitoral. Diário Oficial da República Federativa do Brasil, Brasília, DF, 06.10.2017. Seção 1, p. 1 .

. Supremo Tribunal Federal. Ação direta de inconstitucionalidade $\mathrm{n}^{\circ} 4.650$, Brasília, DF, 17 de dezembro de 2015. Diário de Justiça Eletrônico n. 34, 24 fev. 2016.

. Supremo Tribunal Federal. Ação direta de inconstitucionalidade ${ }^{\circ}$ 5.617, Brasília, DF, 15 de março de 2018. Diário de Justiça Eletrônico n. 57, 23 mar. 2018.

. Supremo Tribunal Federal. Referendo na medida cautelar na arguição de descumprimento fundamental $\mathrm{n}^{\circ} 738$, Brasília, DF, 5 de outubro de 2020. Diário de Justiça Eletrônico n. 260, 29 out. 2020.

. Tribunal Superior Eleitoral. CtaEl - Consulta n 060030647 , de 25 de agosto de 2020. DJE-TSE n. 199, Brasília, DF, 5 out 2020. 